Article

\title{
Accuracy Improvement Method of Energy Storage Utilization with DC Voltage Estimation in Large-Scale Photovoltaic Power Plants
}

\author{
Yeuntae Yoo ${ }^{1}$, Gilsoo Jang ${ }^{1}{ }^{(\mathbb{C}}$, Jeong-Hwan Kim ${ }^{2}$, Iseul Nam ${ }^{2}$, Minhan Yoon ${ }^{3, *}$ \\ and Seungmin Jung $2, *$ (D) \\ 1 School of Electrical Engineering, Korea University, Seoul 136-713, Korea; yooynt@korea.ac.kr (Y.Y.); \\ gjang@korea.ac.kr (G.J.) \\ 2 Department of Electrical Engineering, Hanbat National University, Daejeon 305-719, Korea; \\ kjh7384@hanbat.ac.kr (J.-H.K.); iseu19501@hanbat.ac.kr (I.N.) \\ 3 Department of Electrical Engineering, Tongmyong University, Busan 48520, Korea \\ * Correspondence: minhan.yoon@gmail.com (M.Y.); seungminj@hanbat.ac.kr (S.J.); Tel.: +82-42-821-1096 (S.J.)
}

Received: 27 August 2019; Accepted: 15 October 2019; Published: 15 October 2019

check for updates

\begin{abstract}
In regard to electric devices, currently designed large-scale distributed generation systems require a precise prediction strategy based on the composition of internal component owing to an environmental fluctuating condition and forecasted power variation. A number of renewable resources, such as solar or marine based energies, are made up of a low voltage direct current (DC) network. In addition to actively considering a power compensation plan, these generation systems have negative effects, which can be induced to a connected power system. When a storage is connected to a DC-based generation system on an inner network along with other generators, a precise state analysis plan should back the utilization process. This paper presents a cooperative operating condition, consisting of the shared DC section, which includes photovoltaic (PVs) and energy storage devices. An active storage management plan with voltage-expectation is introduced and compared via a commercialized electro-magnetic transient simulation tool with designed environmental conditions. Owing to their complexity, the case studies were sequentially advanced by dividing state analysis verification and storage device operation.
\end{abstract}

Keywords: PV diagnosis; ESS application; DC power flow; DC system dynamics; hybrid generation system

\section{Introduction}

Solar power still has huge potential and the rate of installation has been growing drastically. A report by the European Photovoltaic Industry Association (EPIA) revealed that the European cumulative photovoltaic (PV) capacity, had increase to more than $120 \mathrm{GW}$ from around $29 \mathrm{GW}$ in 2010 [1]. The report suggests that the PV installation rates will continue to grow through the next decade. A small-scale PV system for residential use is connected to the distribution network, and acts to reduce the electric fee by supplying local demand. An energy management system (EMS) including a building energy management system (BEMS) could be implemented for these kinds of sources, although grid operators concentrate mainly on farm-scale generation systems. Currently, PV plants with a capacity of over $1 \mathrm{GW}$ have been connected worldwide as described in [2], and a number of megawatt (MW)-scaled PV arrays have been configured in those farm networks. These trends will continue to increase, and the production management which covers their stochastic characteristics will pose a challenge in the power system industry. 
To stably and efficiently harness energy from various renewable resources, clustered distribution farms have pursued integrating compensation devices for supporting grid operation with enhanced controllability [3]. These circumstances have been presented by the reported variation resulting from unpredictable natural resources, which is a major issue in renewable energies [4]. Although a clustered farm exhibits better power profile with the in-built smoothing effect, a classic power system still requires advanced solutions by concentrating on predictable usage of storage devices. Currently, most storage applications are oriented to time shifting of real power supply rather than support the connected grid [5]. However, as the requirement in terms of response between cluster and operator expands, further concretion on the controller is required in the power system industry [6].

Recently, the renewable-storage application has been increased due to the increasing large-scale wind farm, something that could significantly affect an integrated power grid, [7]. As a fastidious requirement from grid operator is expected in future power grid, the authors in [8] highlight the importance of both real and reactive power compensation according to the power extracting condition. The reactive power compensation generally focuses on the voltage at local power system; it relies on installed auxiliary devices. On the other hand, an energy storage system (ESS) such as a battery storage could act as real power compensation at the distribution generator side. Both compensation options are based on power-conversion system (PCS) that normally follow an optimized signal generated based on the reference by the main system [9-11]. To achieve a close cooperation with distinct distribution units, conceptual approaches that integrate ESS at the direct current (DC) network have been considered through full converter-based wind turbines in Ref. [12]. Recently, typical DC-based sources including PV and tidal have been extended as an ESS clustered form with other resources as described in Ref. [13]. The main objective of those integration forms is to collaborate among the connected devices, which can enhance the controllability based on the imposed system order [14]. The PV system that is able to compose a hybrid network along with ESS at the DC section is usually composed of a number of solar panels for generating usable input voltage and reasonable power extraction. As described in Refs. $[15,16]$, these specifications generally allow not only electric loss in a cable but also voltage drop below the standard testing condition. Therefore, a direct application of ESS in large-scale PV-based DC clusters is classified as being supported by current analysis at each point. In industrial application forms which are based on inbuilt complementary modes to respond to grid requirements, both limitation and compensation options have to match the harsh power fluctuation of renewable sources [17]. In order to continuously utilize these hybrid features, power flow analysis-based approaches and appropriate ESS design are required.

Meanwhile, the increased utilization of storage in the power system industry has resulted in demands of enhanced storage feature, since power swapping requires fast response capability and suitable energy/power capacity [18]. In the case of conventional ESS applications, utilization of a number of control schemes including hierarchical control were tried as described in Ref. [19]. The described works suggest that we can utilize an ESS configuration to achieve power balance in a power grid where there is presence of several renewable energy and variable loads. However, in previous research, the ESSs were separately composed of the renewable network, and the classified power conversion devices had to respond to the order from the operator based on their own topology. To perform a detailed control within a combined DC circuit that integrates ESS, an operation signal for charging/discharge must be generated reflecting an algorithm based on the expectation of power flow. In case the ESS solution is to be implemented in a PV-integrated DC system, it is deemed that a fast voltage analysis method should support the order decision process in order to take instantaneous voltage fluctuation into the controller [20]. In particular, given that renewable generators based on DC could impose unpredictable profiles on ESS operating processes, specific support strategies are required to manage a transient situation to cover these issues.

In this paper, the main objective is to come up with an ESS compensation scheme that considers exact voltage level so as to implement a power-management plan for a DC-combined system by focusing on the demand of the power system. What distinguishes it from previous research on the 
renewable-ESS integrated networks is that it focused on a method to minimize errors based on detailed circuit analysis rather than systemic utilization. The main analysis in this document focuses on the small power generated by the modules rather than simply focusing on the power extracted from each unit. The entire management process is formed based on power flow analysis for DC systems, which deals with controllable elements that can be reflected on connected equipment. A simulation for verification is designed using the electro-magnetic transient DC (EMTDC) tool. In order to cause a considerable voltage fluctuation according to the output of the connected distributed resources, and to carry out an experiment, a distribution network with a scale of $0.5 \mathrm{~km}$ was constructed considering the real radial system. The ESS model configurations, including control topologies, are utilized to implement the case studies. The case studies focus on the operational accuracy of the proposed control scheme in regards to imposed order from operator.

\section{System Configuration}

\subsection{General Objective}

The typical layout of a MW-class PV farm system is illustrated in Figure 1. A large-scale PV array contains distinct inverters and transformers. In regard to compensation, when an ancillary device for renewable system is considered, the installation location should be at the main bus or sub-station of the PV system. As shown in the figure, a common area is formed by linking the MW-scale solar power generation arrays with a storage device in the DC section. The main purpose is to define possible impact from current flows in the DC section, and preparing a control method for supporting the compensation process in integrated ESS.

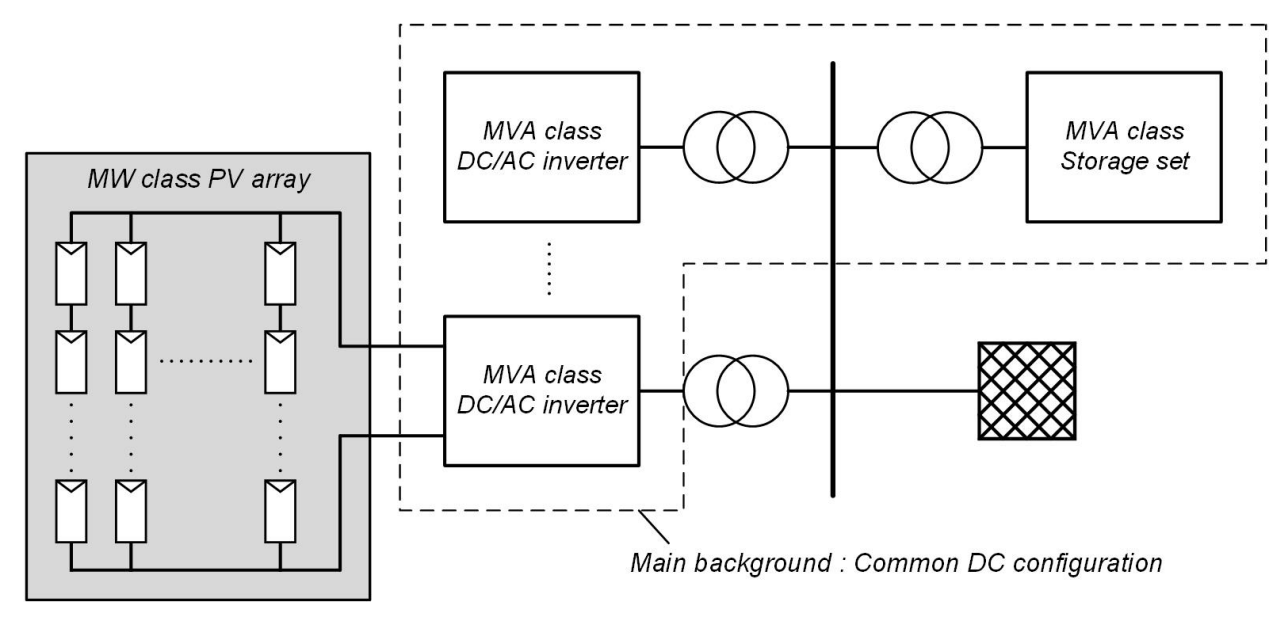

Figure 1. A megawatt (MW)-scale photovoltaic/energy storage system (PV/ESS) for common direct current (DC) configuration.

In various research, large-scale PV plants are modeled with a lumped single generator, by neglecting current flow from each PV module. In terms of power system analysis, this modeling method is fast and useful in identifying the influence of generated power from farm network. However, as mentioned in Ref. [21], a detailed model construction is necessary when deriving a concrete compensation plan is required through confirmation of an instantaneous production of a PV system. It is necessary to select the available topology for industrial use, when implementing DC power flow with a focus on large PV configurations. Generally, to secure the robustness in terms of power extraction, a single MW PV array is connected to the grid through a central inverter topology [22]. With the topology, a mega-voltage ampere (MVA) class DC/AC inverter can accommodate several thousands of PV panels. However, unlike other topologies, the central topology exhibits low levels of flexibility and high mismatching losses due to its huge configuration characteristics. New PV panels for the MW class even consider 
mismatching losses in PV array arrangement through the use of several re-configuration techniques, as described in Ref. [23].

In DC distribution network research, several studies have been conducted in regards to the effects of DC current owing to PV modules. Authors in Refs. [24,25] focused on large-scale integration of the PV system in terms of grid impact such as voltage drop and defined capacity range of a suitable PV generation system. There has been demand in PV module about a DC current analysis. Refs. [26,27] consider actual losses due to a realistic maximum power point tracking (MPPT) errors in large-scale PV system. Reference [23] pursues minimizing mismatching loss by adopting module sorting techniques. A more detailed interpretation is required to establish a more accurate ESS compensation plan in view of the instantaneous power of the internal module. It is likely that the common DC system mentioned in this section will be affected by the current generated by each module, and the resulting DC voltage variation affects the existing ESS control schemes. In the case of PV, since the power generated by each module varies continuously, the voltage calculation of each point through the power flow analysis can be undertaken instantly. By utilizing this values, effective control method for internal ESS can be derived. As a result, data from the external environment can be used to derive its impacts on the internal electric network to use at the main controller. These measures can be useful in the structure of modern PV management systems that use various sensors to obtain environmental information or utilize predictions.

\subsection{Conceptual Design}

Figure 2 represents a conceptual control plan of the proposed method. The entire power from DC-based source is transferred to the connected grid through a main PCS. The ESS is integrated into a common DC link using a DC/DC converter. Since the compensation devices in these structures should be located at the front of the main PCS, the power flow from DC generators (PV or wave) should pass through the junction of the ESS [28]. Through this flow, the integrated storage device is directly affected by the electrical conditions with respect to the voltage level which is among the main reference signal of the control process. The main purpose of the compensation devices is to store excess output power (above the reference signal) and utilize a bi-directional PCS to discharge the stored energy on the operators' request. This paper describes DC power flow analysis, including DC network characteristics for PV generators. Section 2 covers a basic system description.

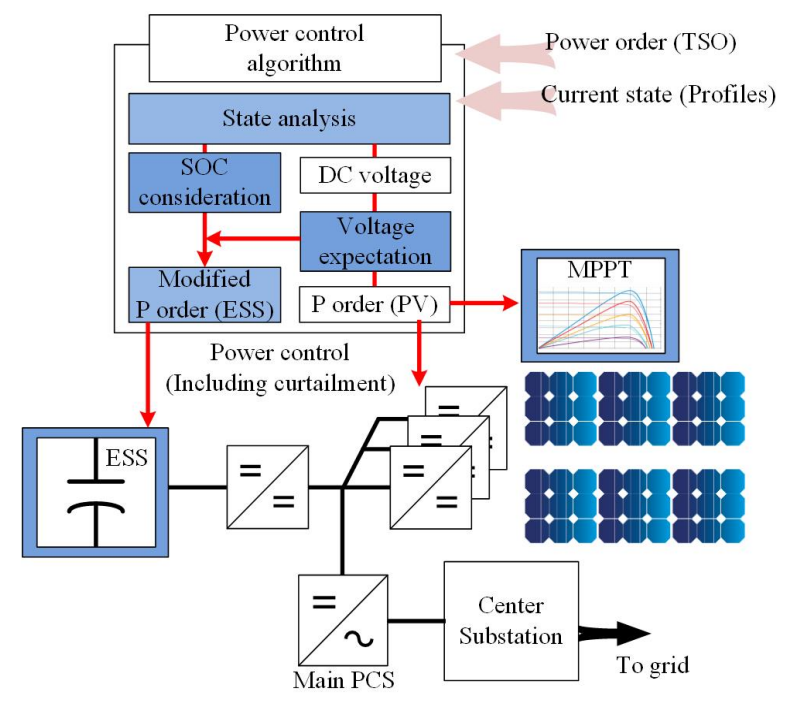

Figure 2. Power control concept of ESS-combined PV system. 


\subsection{Alternating Current/Direct Current (AC/DC) Hybrid System}

General voltage-sourced converter (VSC)-based structures are established at the front of generation system, which means that the generated power must pass through a DC section through its own converter. Therefore, as described in Ref. [29], the power supply from combined DC network could experience more ohmic losses compared to other single generation system. There are several studies on the DC farm topologies to increase efficiency and mitigate these issues as a result [30]. The conventional DC-based farm have extended the available farm scale through the increase in number of the sources and boosting level of the classified voltage.

The model utilized in this paper focuses on coupled power resources structure constructed in DC. Once the ESS is planned to attach to the structure, it should be placed in front of the main sub-system and follow the operators' order. The ESS applications applied in the DC section are based on improved usability. However, the electrical flow in the low voltage section can result to unstable voltage conditions in terms of compensation device usage. As a compensation device in the common DC network is expected in several renewable energy sources, an advanced technique based on DC analysis is required to maintain the system's performance.

\subsection{Network}

\subsubsection{Generation System}

This paper presents a hybrid system that installs a common DC network for PV and ESS. If used in real-time conditions, then a fast computation method management should be composed to handle electronic based resources. Prior to defining the relationship between order and voltage level, a general power flow analysis have to compose focused on power production. The flow injected by PV modules can be given by the sum of the power produced from each module with incurred losses as follows:

$$
P_{\mathrm{PV}}=\sum_{l=1}^{L} \sum_{n=1}^{\mathrm{N}} P_{n}-\sum_{l=1}^{L} \sum_{n=1}^{\mathrm{N}} P_{\text {loss }}(n)
$$

where, $P_{P V}$ is total output power from PVs, $P_{n}$ is output power from nth module, $P_{\text {loss }}$ is generated loss in the cable, $L$ is total number of arrays, and $N$ is total number of modules.

The ohmic loss can be defined as follows:

$$
P_{\text {loss }}=r_{n n+1} \frac{P_{n n+1}^{2}}{V_{n}^{2}}
$$

where, $P_{n n+1}$ is real power flow from module $n$ to $n+1, R_{n n+1}$ is resistance value between module $n$ and $n+1$, and $V_{n}$ is voltage magnitude of module $n$.

A PV system generates real power according to the irradiation profile by utilizing applied converter based on the designed curve which is related to the power coefficient. The PCS selects the power point within the operational range to extract the maximum available power. This paper considers the ESS application in the DC link as a power compensation device. If the extracted power of the hybrid system exceeds the designated order by the operator, the ESS is activated to support the entire output power based on the operator's order. It can be composed when the total DC flow of the entire circuit is analyzed using appropriate formulas. The total DC flow with capacity constraint can be defined as in Equation (3), and DC current flow to utilize flow analysis as shown is as follows:

$$
P_{\mathrm{dc}}=P_{P V}+P_{E S S}, \quad\left|P_{E S S}\right| \leq S_{d c-d c}
$$


where, $P_{d c}$ is real power injection from DC system, $P_{E S S}$ charging/discharging quantity from ESS, and $S_{d c-d c}$ is the Power capacity of DC/DC converter for the ESS.

$$
i_{\mathrm{dc}}=\sqrt{g_{\mathrm{eq}} \cdot P_{\mathrm{ref}}}
$$

where, $i_{d c}$ is current flow at the converter, $g_{e q}$ is equivalent admittance of PCS, and $P_{\text {ref }}$ is reference signal of real power for the PCS.

The constraint in the limit process can be defined as follows:

$$
\max P_{d c} \leq \sqrt{S_{P C S}^{2}-Q_{P C S}^{2}}
$$

where, $S_{p c s}$ is power capacity of main PCS, and $Q_{P C S}$ is reactive power production from main PCS.

Since it is expected that several modules are integrated into a single array in a PV farm, a voltage variation of the $\mathrm{DC}$ side is dependent on the PVs' output power. When an operator wants to handle demand response through applied ESS (charging or discharge), the voltage variations induced in the DC network have to be reflected.

\subsubsection{Storage System}

The application of the ESS in renewable energy should consider both the own operational state and the generated signals from the grid operator. In general, there is a standardized form of the ESS in an industrial power system. (1) Usually, the ESS connection point provides the point of common coupling (PCC) for renewable energy. (2) To maintain the DC level of the battery, an ESS should apply a distinct DC/DC conversion device. (3) An ESS performs charge/discharge based on imposed limitation (voltage) or a direct order. In case of voltage focused solutions, previous research utilized the specified voltage level as the limit, which was utilized to decide whether the ESS was attached or detached to the grid. Figure 3 describes the concept with a flywheel solution, which employs a super-conducting rotating device [31]. This application relies on a bi-directional controller to control electrical flow and determine whether it charges or discharges by detecting the voltage limitation. In this topology, the controller can strictly manage the voltage levels within the specified range. However, the supplied power from the ESS cannot be defined as a constant value which is able to utilize power balancing. The proposed plan proposes storing and releasing real power with a strict control signal instead of voltage limitation. A bi-directional PCS focuses on designated order to handle entire output power from the DC network.

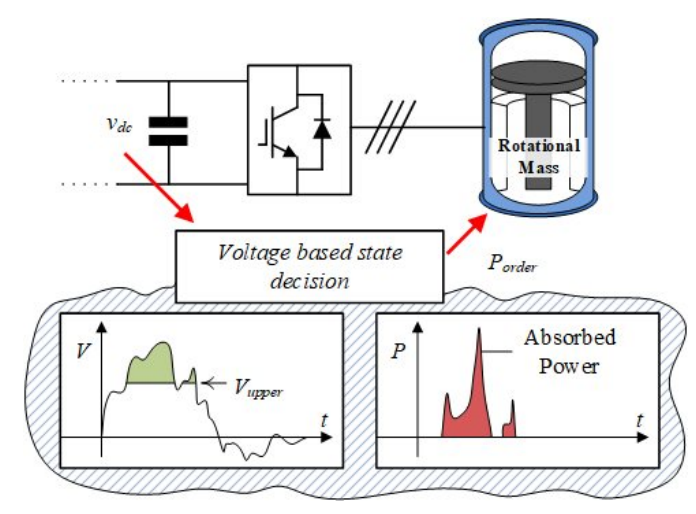

Figure 3. Voltage limitation-based ESS control scheme.

In case of order for ESS, both charging and discharging signals can be represented with the connected PV as follows:

$$
P_{E S S}(t)=P_{d c}-\sum P_{P V}(t)
$$


In order to correctly extract the power signal, the proposed ESS controller adopts additional DC analysis blocks to enhance the accuracy of charging/discharging signals.

\section{DC Flow Analysis}

To perform the current flow analysis about a target DC network, an electric based circuit model should first be developed. In order to estimate the voltage variation of each section based on the power extraction, an equivalent circuit was developed for power flow analysis.

In case of the general analysis of the PV circuit for current estimation, the resistance in the circuit is divided into two categories (shunt and series) as shown in Figure 4 to advance it in terms of simplification [32]. With this simplification, environmental factors such as irradiation (G) can be reflected in output current expression. On the PV system, however, since a current flows through the negative pole which is for grounding, for detailed current analysis, a method to reflect this circumstance should be derived. In Ref. [33], a method is derived to eliminate the leakage current in consideration of the earth impedance. In this regard, a method of applying the grounding components to the detailed analysis is continually being studied. In addition, although the general method introduces each environmental variable as a constant value to advance the prediction of current flow, it is difficult for these methods to reflect a real-time environment. In this paper, we focused on the method of deriving the amount of current based on real-time power output, and tried to improve the accuracy by minimizing the variables. Figure 5 shows a simplified circuit which includes PV, ESS and DC/AC inverter to connect the main grid. The resistance components between each PV module were imposed in the circuit for purposes of clearly describing voltage fluctuation on a low-voltage DC network. Reflection of the inner voltage variation condition for large-scale PV generation system is a demanded feature which is also considered in commercialized simulation tool as well. In this paper, the resistance components at the negative DC pole which is usually considered as ground section is utilized to improve the accuracy of voltage calculation.

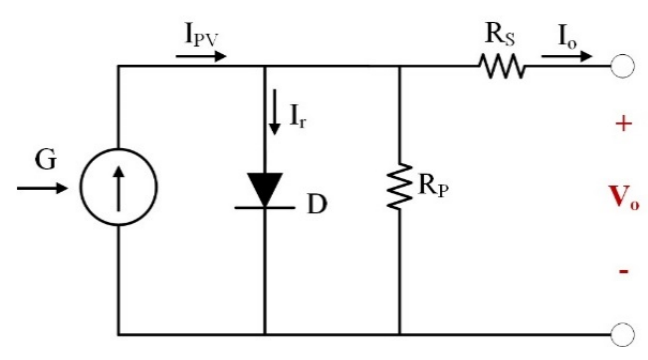

Figure 4. Equivalent circuit of single diode model for PV.

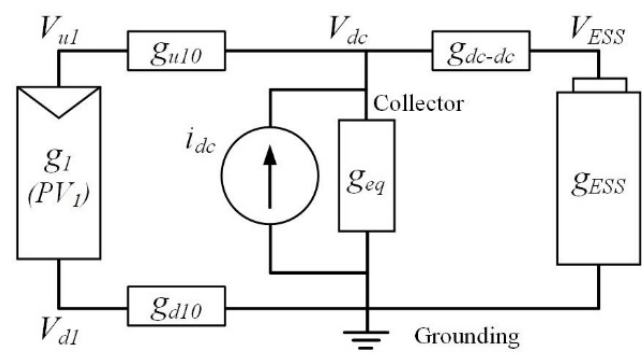

Figure 5. Power flow analysis model for DC.

Firstly, the equivalent component of the PV module in the figure is based on a single module; the basic objective of the described circuit is to derive a mathematical expression for voltage level of each section including the front of the inverter device. In the case of the PCS for a PV system, since the AC side is connected to stable grid network, it is capable of converging as an equivalent circuit. To reflect the voltage variation in the DC section, the Norton equivalent method is applied 
in this study. When DC network analysis is imposed into the PV system, there is a need to imply the power extracting condition for each module in current flow form. The output power of the PV module can be modified to obtain an equivalent circuit with negative values if each module is considered as an admittance component. In case of ESS component, both charging and discharging power can be implemented using an equation that has described modeling processes. Each component in the figure can be transformed using the components mentioned as follows:

$$
\left|\begin{array}{cccc}
g_{1}+g_{u 10} & -g_{1} & -g_{u 10} & 0 \\
-g_{1} & g_{1}+g_{d 10} & 0 & 0 \\
-g_{u 10} & 0 & g_{u 10}+g_{e q}+g_{p c s} & -g_{e q} \\
0 & 0 & -g_{e q} & g_{e q}+g_{E S S}
\end{array} \| \begin{array}{c}
V_{u 1} \\
V_{d 1} \\
V_{d c} \\
V_{E S S}
\end{array}\right|=\left|\begin{array}{c}
0 \\
0 \\
i_{d c} \\
0
\end{array}\right|
$$

The DC section of single array would consist directly connected PV module, main PCS for subsystem, and DC/DC convertor for introduced storage devices. The three basic models could be transferred as an electrical component in order to proceed as an iterative calculation process. The iteration requires input parameters including a known quantity to derive each section's voltage levels which are considered as unknown values in the circuit elements. The system input parameters include admittance values, which are repeatedly updated with extracted power from series-connected PV modules, and derived based on Equation (8).

$$
g_{n}=-\frac{P_{n}}{\left(V_{u n}-V_{d n}\right)^{2}}
$$

The voltage for PV modules considers both the upper and lower side and are continuously modified throughout the iteration process as unknown values. The admittance component of ESS are as follows in Equation (9) by assuming shared grounding option.

$$
g_{E S S}=-\frac{P_{E S S}}{V_{E S S}^{2}}
$$

Since the voltage level of each section is dependent on electrical current via power flows, the modified values would continuously affect the admittance component until every input parameter is converged. The corresponding current of PCS would hold the relevant DC power flow as a strict component in the system matrix. To perform the iteration, which is considered as a main calculation, an inverse matrix is utilized to progress the iteration as described in Equation (10).

$$
[V]=[g]^{-1} \times[I]
$$

The contents of Figure 5 are based on single PV module; hence, large-scaled PV generation system requires further dimensional matrix. If $\mathrm{n}$ modules are added, the circuit will be expanded as mentioned above, which results in a change in the basic equation as follows in (11).

When adding $n$ modules, an $n \times 2$ matrix size expansion is progressed on an existing equation. If this equation is analyzed in detail, it is possible to consider a difference of production by large modules and organize an equation about the profile of each module with the required data.

$$
\begin{array}{|cccccc||c}
g_{1}+g_{u 1 n} & -g_{1} & -g_{u 1 n} & 0 & 0 & 0 \\
-g_{1} & g_{1}+g_{d 1 n} & 0 & -g_{d 1 n} & 0 & 0 \\
-g_{u 1 n} & 0 & g_{u 1 n}+g_{n}+g_{u n 0} & -g_{n} & -g_{u n 0} & 0 \\
0 & -g_{d 1 n} & -g_{n} & g_{d 1 n}+g_{n}+g_{d n 0} & 0 & 0 & V_{u 1} \\
0 & 0 & -g_{u n 0} & 0 & g_{u n 0}+g_{p c s}+g_{e q} & -g_{e q} \\
V_{d 1} \\
V_{u n} \\
V_{d n} \\
V_{d c} \\
V_{\text {ess }}
\end{array}
$$




\section{Simulation}

\subsection{Simulation Design}

In order to assess the proposed control method, a detailed simulation is conducted using a power-system computer aided design (PSCAD). Figure 6 shows a layout of the PV connected distribution network, that utilizes the linked DC section. The PV generation system in the network has a nominal power capacity of $400 \mathrm{kVA}$. To verify the proposed method, a single PV generation system includes 120 parallel/40 series modules. The PV system is connected to the displayed distribution network by utilizing the central inverter topology. The DC network also includes the ESS model to verify the proposed reference modification method. The distance data about the distribution network is reflected in pi-line which is the base model in PSCAD/EMTDC. The network information, which is used for utility grid construction, is shown in Table 1 including the PI-line distances in Figure 6.

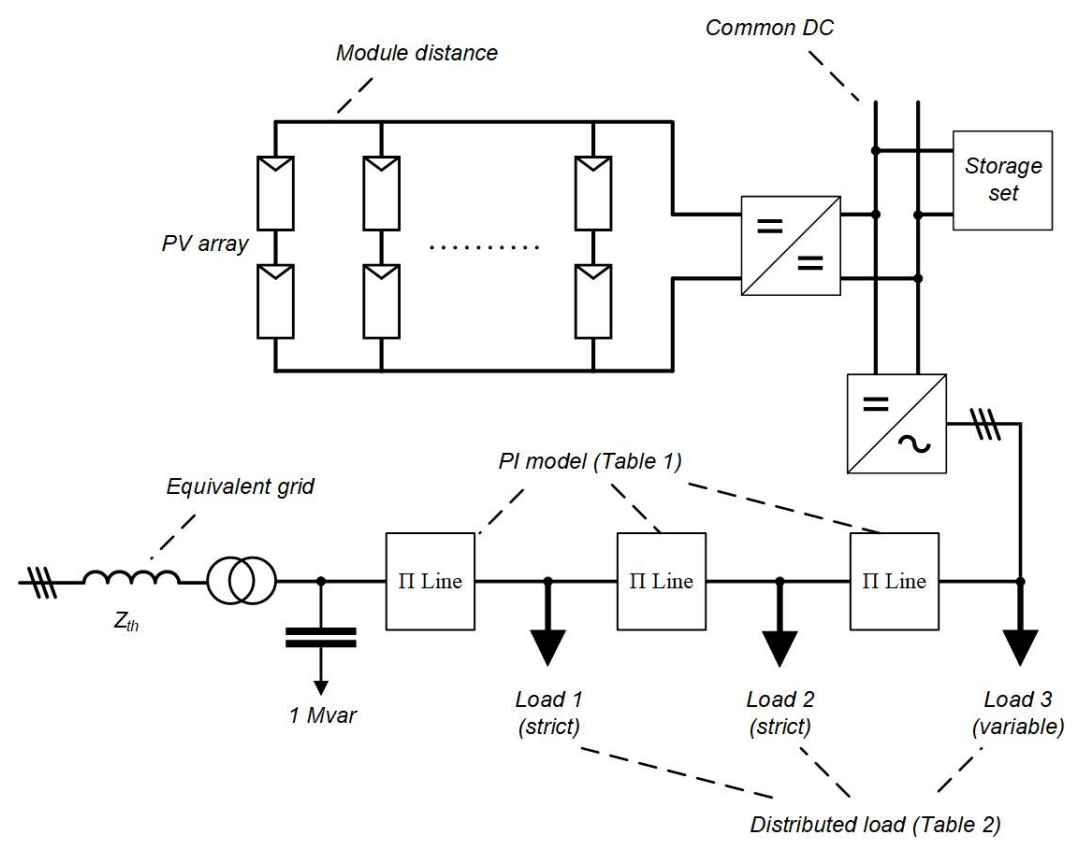

Figure 6. Simulated distribution network including MW-scale PV/ESS.

Table 1. Numerical data for the simulation.

\begin{tabular}{ccc}
\hline Specific Data & Value & Unit \\
\hline Rated AC voltage & 22.9 & $\mathrm{kV}$ \\
Rated DC voltage & 500 & $\mathrm{~V}$ \\
Distance between each module & 0.5 & Meter \\
Number of load & 3 & \\
Rated energy of ESS & 200 & $\mathrm{kWh}$ \\
Rated power of ESS & 200 & $\mathrm{~kW}$ \\
Rated power of PV system & 1200 & $\mathrm{~kW}$ \\
PI-line distance & 500 & Meter \\
Substation voltage (HV) & 154 & $\mathrm{kV}$ \\
Short-circuit ratio of utility grid & 15 & \\
X/R ratio of utility grid & 15 & \\
\hline
\end{tabular}

Figure 7 describes the simulations of the designed PV production. PV system extracts real power based on the radiation data as per the specific coefficient values. A small variation of the extracted power could affect the operation of the connected ESS. To check ESS control effects under certain conditions, unexpected variations need to be checked. Table 2 includes applied load parameters for the case studies. The main objective of the simulation is to confirm that the proposed method 
shows better reliability compared to rated voltage-based control. The voltage controller is configured based on an existing solar-ESS combined control, which takes into account the sensitivity between voltage and power production [34]. The method generally operates in combination with on-load tap changer (OLTC), yet it depends on the characteristics of the connected power system. Therefore, in this paper, we try to compare the results when only the main controller was applied. To check ESS operation, a number of discrete load variations were designed for each scenario. The simulation mainly considers the charging/discharging processes to confirm profile accuracy in regards to reference signal. The reference signal is designed to change depending on the load condition, while the configured case studies and entire simulation time is set to $10 \mathrm{~s}$ including the start-up time. Assuming abrupt load variation, a number of orders changing sections (for charging and discharging) are designed for the simulation. A few of the load changes are executed by stages as displayed in Figure 8. The momentary load changes $(75 \mathrm{~kW})$ generates a demand about the order change for reducing the distribution network burden.

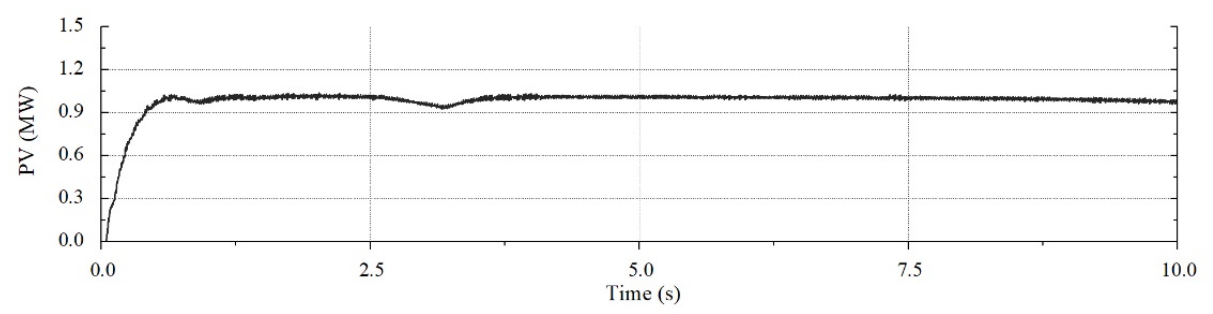

Figure 7. Basic PV production in case study.

Table 2. Simulated case study description.

\begin{tabular}{cc}
\hline Imposed Control Method & $\begin{array}{c}\text { Strict Voltage Control Method, } \\
\text { Proposed Control Method }\end{array}$ \\
\hline Simulation time & $10 \mathrm{~s}$ \\
\hline Base load condition & Load 1: $900 \mathrm{~kW}$ \\
(Real power) & Load 2: $1500 \mathrm{~kW}$ \\
Load 3: $1380 \mathrm{~kW}$ \\
\hline Load increase sections & $2.5-3,3.5-4,8-8.5 \mathrm{~s}(75 \mathrm{~kW})$ \\
(Load 3) & $3-3.5,4-4.5 \mathrm{~s}(150 \mathrm{~kW})$ \\
\hline Load decrease sections & $5-5.5,6-6.5,8.5-9 \mathrm{~s}(75 \mathrm{~kW})$ \\
(Load 3) & $5.5-6,6.5-7 \mathrm{~s}(150 \mathrm{~kW})$ \\
\hline
\end{tabular}

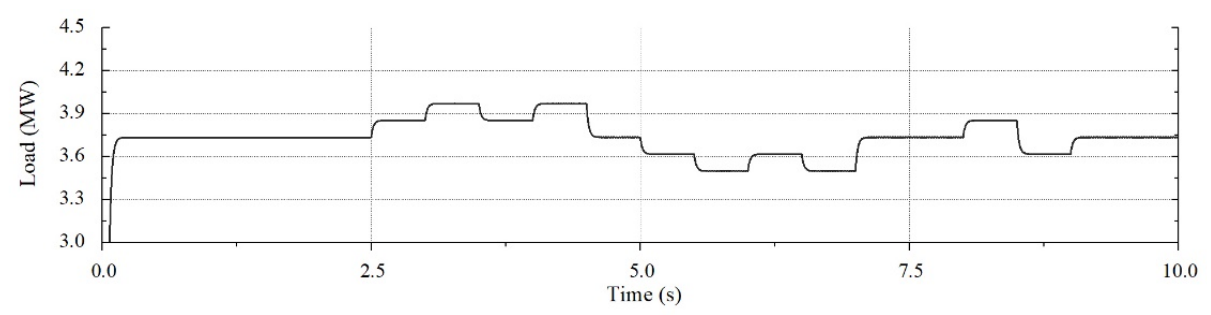

Figure 8. Simulated load variation in case study.

Without ESS, the connected substation should supply the required power based on the change of the distribution network. However, with ESS, a distribution system operator would attempt to cover the unexpected variation through the support of ESS due to operation responsibility (i.e., rate of power change). This forms the basis of the operational objective of the ESS in this scenario. The total power supplied from the grid with non-ESS condition is shown in Figure 9. Based on this condition, ESS charging/discharging would be handled through applied methods. The basic algorithm using the 
power command and the rated voltage is entered to obtain an effect firstly, and a comparison analysis with the proposed use is advanced.

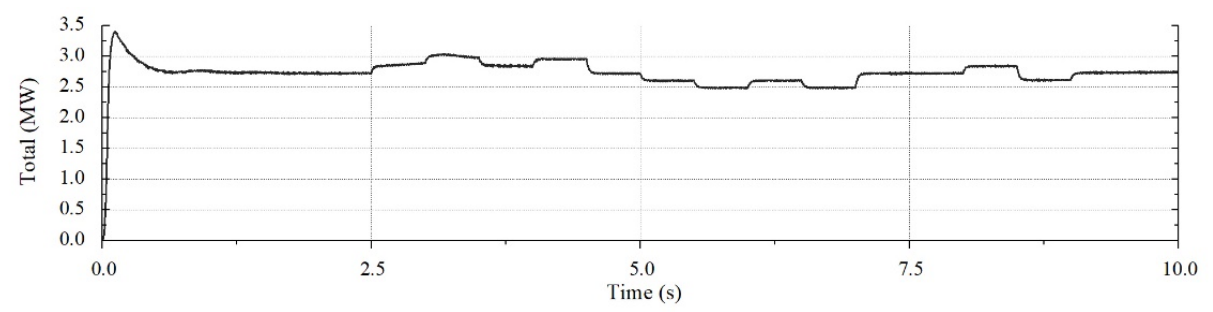

Figure 9. Power supplied quantity from main grid (non-ESS).

\subsection{Simulation Results}

Figure 10 shows a power production curve of the common DC system including ESS output with rated voltage level consideration. The ESS charges and discharges depending on the load variation on Figure 8. It can be confirmed that the power supplied from DC, which depends mainly on the amount of PV generation, has been modified according to the complementary power of ESS corresponding to the increase in load of each designed section. Depending on the total output power including extracted power from the ESS, unexpected voltage fluctuations can occur in the DC system, and the main objective of the simulation is to compare the response ability. Since the control was established to reduce the variations of the power supplied, the quantity from the grid can be attenuated as illustrated in Figure 11. Compared with the general conditions in Figure 9, the supplied power from the grid can avoid discrete changes through ESS compensation. However, a minor variation is still exhibited on the power curve, hence more precise compensations are still required.

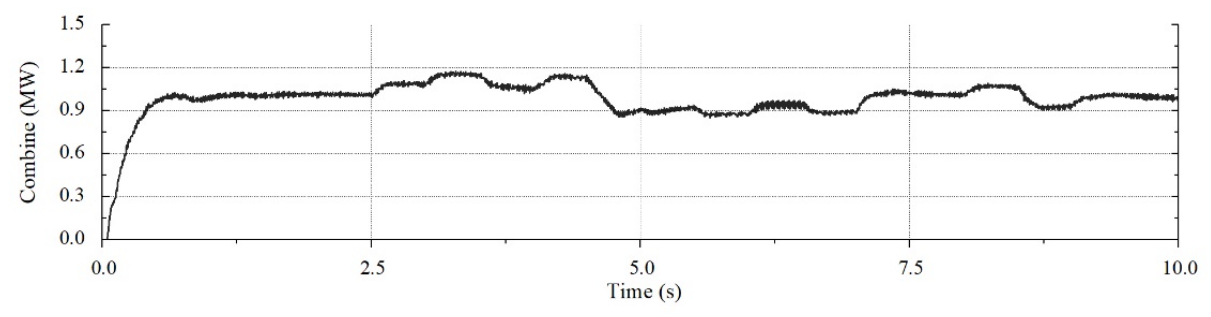

Figure 10. Combined power production of DC network (ESS-strict voltage control).

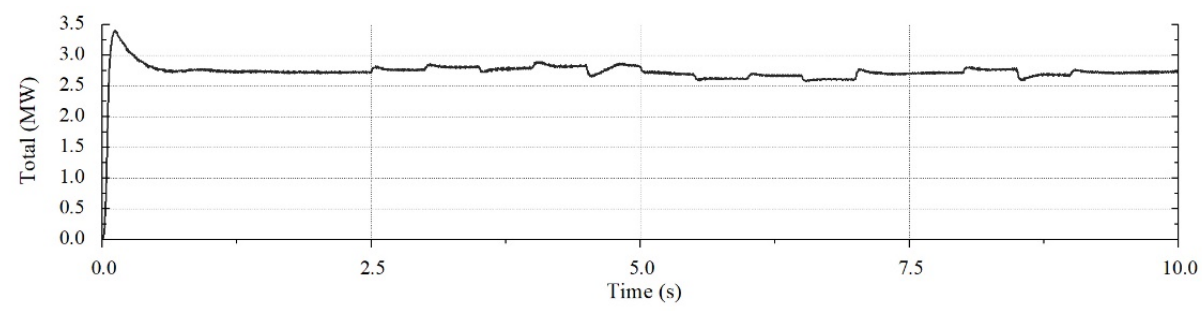

Figure 11. Quantity of power supplied from main grid (ESS-strict voltage control).

The proposed flow expectation method is applied to the same simulating condition. In regards to precise voltage condition, the proposed control attempts to reduce the previous errors and smoothen the power supplied quantity from the grid.

The power production is handled within the rated capacity and the differences between control methods are generated depending on the precision of controllers in terms of voltage. The highlighted charging and discharging sections (2.5-4.5 and 5-7 s) are described in Figure 12. In both cases Figure 12a,b, a strict voltage control method finds it difficult to detect DC voltage variations, and generate mismatches for both sections. The method triggers ESS operation with signal and supports the grid 
according to the voltage mismatch through comparison of the rated voltage $(500 \mathrm{~V})$. Since storage sets perform according to the power capacity, there could be double error generated which could affect the grid power balance. The ESS output curves of the proposed method are displayed together with strict voltage control. The mismatches are reduced in both control modes as described in the figures, and the reliability of the compensation significantly improved in terms of solution. Without the initialization section, the power supplied by ESS almost coincides with the increased variable load value. The power supplied quantity from the main substation is illustrated in Figure 13. Compared with the previous state, as shown in the figure, the fluctuation generated is significantly reduced. The control error via the general method is modified in the case of both charging and discharging processes.

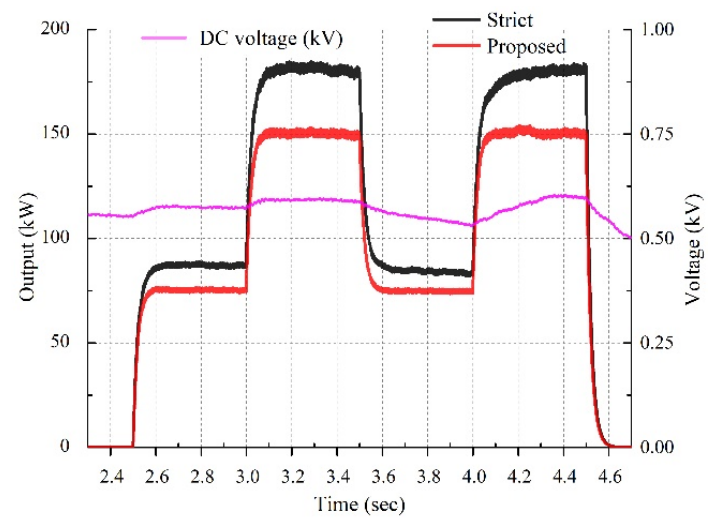

(a)

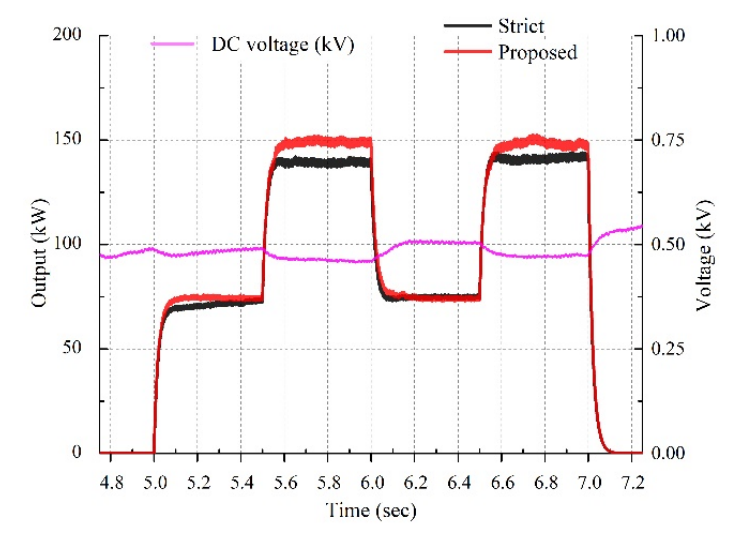

(b)

Figure 12. Detailed power compensation quantities for ESS with DC voltage variations (a) extracted power quantity in the discharging section ( 2.5 to $4.5 \mathrm{~s}$ ); (b) absorbed power quantity in the charging section ( 5 to $7 \mathrm{~s})$.

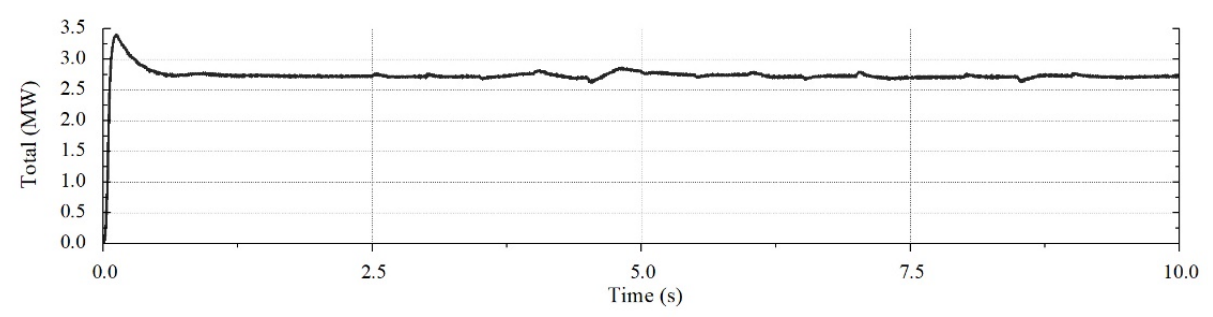

Figure 13. Quantity of power supplied from main grid (ESS-proposed control).

The total mismatch quantity for both methods in terms of power support is presented in Table 3. The difference between the demanded control quantity (calculated by strict power references) and the profile is reduced for both control modes, and the reliability of the profiled quantity is significantly improved in regard to energy compensation. In particular, error generated in the discharging state is significantly reduced with the proposed controller.

Table 3. Numerical results for imposed order and profiled quantity.

\begin{tabular}{cccccc}
\hline Control & ESS Mode & Demanded Quantity (Wh) & Accomplished Quantity (Wh) & Gap(Wh) & Error (\%) \\
\hline \multirow{2}{*}{ Strict voltage } & Charging & 145.83 & 136.304 & 9.526 & 6.53 \\
& Discharging & 145.83 & 167.877 & 22.047 & 15.12 \\
\hline \multirow{2}{*}{ Proposed } & Charging & 145.83 & 140.912 & 4.918 & 3.37 \\
& Discharging & 145.83 & 143.834 & 1.996 & 1.37 \\
\hline
\end{tabular}

\section{Conclusions}

This paper proposes a modified compensation method for the MW-scaled AC-DC hybrid systems such as storage devices. To perform the ESS operation with an effective reference order, 
a voltage-estimation method was formulated and adopted in the designed generation system. Verification of the performance improvement in regard to the real power management that responds to the order is verified through case studies. According to the changed state in terms of load, the proposed controller generated a precise order considering the real power extraction from the DC network. The MW-scaled DC networks with different sources experience voltage fluctuation when interworking with the grid. In case of the proposed method, however, it is required to establish the power production of the module as an input signal since credibility is required not only on the PV module but also on the applied sensors. When pursuing detailed management of large-scale DC systems, the application could be considered by the ESS operator. In general, the large-scale DC networks with diverse sources have voltage fluctuation when interworking with the grid. The designed method is based on a multiple PV system, the active support plan using ESS is able to further expand large DC system. Even if the error mitigation on the basis of the order is a minor issue in certain system, the improvement can be useful for the ESS management process with respect to state of charge. The controller will improve estimation accuracy of the remaining amount for the ESS, and this can help support operational accuracy.

Author Contributions: Conceptualization, Y.Y. and S.J.; Methodology, S.J.; Software, Y.Y.; Validation, Y.Y., and S.J.; Formal Analysis, J.-H.K., I.N. and M.Y.; Investigation, J.-H.K., I.N. and M.Y.; Data Curation, J.-H.K., I.N. and M.Y.; Writing-Original Draft Preparation, S.J.; Writing-Review and Editing, S.J. and G.J.; Supervision, S.J.; Project Administration, S.J. and G.J.; Funding Acquisition, S.J.

Funding: This work was supported by the National Research Foundation Grant (No. 2018R1C1B5030524) and the Korea Institute of Energy Technology Evaluation and Planning/MOTIE (No. 20184030201900) funded by the Korean government.

Conflicts of Interest: The authors declare no conflict of interest.

\section{Nomenclature}

$g_{n} \quad$ Equivalent admittance of nth module

guno Admittance of positive side DC cable between nth module and collector

$g_{d n o} \quad$ Admittance of negative side DC cable between nth module and ground

$g_{d c-d c} \quad$ Equivalent admittance about DC/DC convertor for ESS

$g_{\text {ESS }} \quad$ Equivalent admittance of ESS module

G Solar irradiation $\left(\mathrm{W} / \mathrm{m}^{2}\right)$

IPV $\quad$ PV current in single diode model

$\mathrm{I}_{\mathrm{r}} \quad$ Reverse saturation current of PV

$\mathrm{I}_{\mathrm{SC}} \quad$ Short circuit current of PV

$\mathrm{I}_{\mathrm{O}} \quad$ Output current in single diode model

$\mathrm{R}_{\mathrm{P}} \quad$ Shunt resistance of PV

$\mathrm{R}_{\mathrm{S}} \quad$ Series resistance of PV

$V_{u n} \quad$ Upper-side voltage of nth module

$V_{d n} \quad$ Lower-side voltage of nth module

$V_{d c} \quad$ Collector voltage

$V_{E S S} \quad$ Induced ESS voltage

\section{References}

1. Rakhshani, E.; Rouzbehi, K.; Sánchez, A.J.; Tobar, A.C.; Pouresmaeil, E. Integration of Large Scale PV-Based Generation into Power Systems: A Survey. Energies 2019, 12, 1425. [CrossRef]

2. Biggest Solar Power Plants. Mechanical, Electrical and Electronics Engineers. Available online: https: //meee-services.com/biggest-solar-power-plants (accessed on 30 August 2018).

3. Su, M.; Luo, C.; Hou, X.; Yuan, W.; Liu, Z.; Han, H.; Guerrero, J.M. A Communication-Free Decentralized Control for Grid-Connected Cascaded PV Inverters. Energies 2018, 11, 1375. [CrossRef]

4. Osório, G.J.; Shafie-khah, M.; Lujano-Rojas, J.M.; Catalão, J.P. Scheduling Model for Renewable Energy Sources Integration in an Insular Power System. Energies 2018, 11, 144. [CrossRef] 
5. Subramani, G.; Ramachandaramurthy, V.K.; Padmanaban, S.; Mihet-Popa, L.; Blaabjerg, F.; Guerrero, J.M. Grid-tied photovoltaic and battery storage systems with Malaysian electricity tariff-A review on maximum demand shaving. Energies 2017, 10, 1884. [CrossRef]

6. Zeng, Z.; Yang, H.; Zhao, R.; Cheng, C. Topologies and control strategies of multi-functional grid-connected inverters for power quality enhancement: A comprehensive review. Renew. Sustain. Energy Rev. 2013, 24, 223-270. [CrossRef]

7. Miao, L.; Wen, J.; Xie, H.; Yue, C.; Lee, W. Coordinated control strategy of wind turbine generator and energy storage equipment for frequency support. IEEE Trans. Ind. Appl. 2015, 51, 2732-2742. [CrossRef]

8. Bird, L.; Cochran, J.; Wang, X. Wind and Solar Energy Curtailment: Experience and Practices in the United States; NREL: Golden, CO, USA, 2014.

9. Chen, P.; Thiringer, T. Analysis of Energy Curtailment and Capacity Over installation to Maximize Wind Turbine Profit Considering Electricity Price-Wind Correlation. IEEE Trans. Sustain. Energy 2017, 8, 1406-1414. [CrossRef]

10. Saez-de-Ibarra, A.; Milo, A.; Gaztañaga, H.; Debusschere, V.; Bacha, S. Co-Optimization of Storage System Sizing and Control Strategy for Intelligent Photovoltaic Power Plants Market Integration. IEEE Trans. Sustain. Energy 2016, 7, 1749-1761. [CrossRef]

11. Stimoniaris, D.; Tsiamitros, D.; Dialynas, E. Improved Energy Storage Management and PV-Active Power Control Infrastructure and Strategies for Microgrids. IEEE Trans. Power Syst. 2016, 31, 813-820. [CrossRef]

12. Shi, G.; Zhang, J.; Cai, X.; Zhu, M. Decoupling control of series-connected DC wind turbines with energy storage system for offshore DC wind farm. In Proceedings of the IEEE 7th International Symposium on Power Electronics for Distributed Generation Systems (PEDG), Vancouver, BC, Canada, 27-30 June 2016.

13. Vargas, L.S.; Bustos-Turu, G.; Larraín, F. Wind Power Curtailment and Energy Storage in Transmission Congestion Management Considering Power Plants Ramp Rates. IEEE Trans. Power Syst. 2015, 30, 2498-2506. [CrossRef]

14. Knap, V.; Chaudhary, S.K.; Stroe, D.; Swierczynski, M.; Craciun, B.; Teodorescu, R. Sizing of an Energy Storage System for Grid Inertial Response and Primary Frequency Reserve. IEEE Trans. Power Syst. 2016, 31, 3447-3456. [CrossRef]

15. Zhang, H.; Yue, D.; Xie, X. Robust Optimization for Dynamic Economic Dispatch under Wind Power Uncertainty with Different Levels of Uncertainty Budget. IEEE Access 2016, 4, 7633-7644. [CrossRef]

16. Byungdoo, J.; Hyun, K.; Heechan, K.; Hansang, L. Development of a Novel Charging Algorithm for On-board ESS in DC Train through Weight Modification. J. Electr. Eng. Technol. 2014, 9, 1795-1804.

17. Yang, J.; Fletcher, J.E.; O'Reilly, J. Multiterminal DC wind farm collection grid internal fault analysis and protection design. IEEE Trans. Power Del. 2010, 25, 2903-2912. [CrossRef]

18. Kaipia, T.; Salonen, P.; Lassila, J.; Partanen, J. Possibilities of the low voltage DC distribution systems. In Proceedings of the NORDAC Conference, Stockholm, Sweden, 30 August-2 September 2006.

19. Dzamarija, M.; Keane, A. Autonomous curtailment control in distributed generation planning. IEEE Trans. Smart Grid 2016, 7, 1337-1345. [CrossRef]

20. Jung, S.; Yoon, Y.-T.; Jang, G. Adaptive Curtailment Plan with Energy Storage for AC/DC Combined Distribution Systems. Sustainability 2016, 8, 818. [CrossRef]

21. Yazdani, A.; Dash, P.P. A Control Methodology and Characterization of Dynamics for a Photovoltaic (PV) System Interfaced with a Distribution Network. IEEE Trans. Power Deliv. 2009, 24, 1538-1551. [CrossRef]

22. Cabrera-Tobar, A.; Bullich-Massagué, E.; Aragüés-Peñalba, M.; Gomis-Bellmunt, O. Topologies for large scale photovoltaic power plants. Renew. Sustain. Energy Rev. 2016, 59, 309-319. [CrossRef]

23. Mansur, A.A.; Amin, M.R.; Islam, K.K. Performance Comparison of Mismatch Power Loss Minimization Techniques in Series-Parallel PV Array Configurations. Energies 2019, 12, 874. [CrossRef]

24. Widén, J.; Wäckelgård, E.; Paatero, J.; Lund, P. Impacts of distributed photovoltaics on network voltages: Stochastic simulations of three Swedish low-voltage distribution grids. Electr. Power Syst. Res. 2010, 80, 1562-1571. [CrossRef]

25. Paatero, J.V.; Lund, P.D. Effects of large-scale photovoltaic power integration on electricity distribution networks. Renew. Energy 2007, 32, 216-234. [CrossRef]

26. Koutroulis, E.; Blaabjerg, F. A New Technique for Tracking the Global Maximum Power Point of PV Arrays Operating Under Partial-Shading Conditions. IEEE J. Photovolt. 2012, 2, 184-190. [CrossRef] 
27. Karanayil, B.; Ceballos, S.; Pou, J. Maximum Power Point Controller for Large Scale Photovoltaic Power Plants Using Central Inverters under Partial Shading Conditions. IEEE Trans. Power Electron. 2018, 34, 3098-3109. [CrossRef]

28. Garces, A. A Linear Three-Phase Load Flow for Power Distribution Systems. IEEE Trans. Power Syst. 2016, 31, 827-828. [CrossRef]

29. Karthikeyan, V.; Gupta, R. Multiple-Input Configuration of Isolated Bidirectional DC-DC Converter for Power Flow Control in Combinational Battery Storage. IEEE Trans. Ind. Inform. 2018, 14, 2-11. [CrossRef]

30. Chew, B.S.H.; Xu, Y.; Wu, Q. Voltage Balancing for Bipolar DC Distribution Grids: A Power Flow Based Binary Integer Multi-Objective Optimization Approach. IEEE Trans. Power Syst. 2019, 34, 28-39. [CrossRef]

31. Jabr, R.A.; Džafić, I. Solution of DC Railway Traction Power Flow Systems Including Limited Network Receptivity. IEEE Trans. Power Syst. 2018, 33, 962-969. [CrossRef]

32. Jayalakshmi, N.S.; Gaonkar, D.N.; Adarsh, S.; Sunil, S. A control strategy for power management in a PV-battery hybrid system with MPPT. In Proceedings of the 2016 IEEE 1st International Conference on Power Electronics, Intelligent Control and Energy Systems (ICPEICES), Delhi, India, 4-6 July 2016; pp. 1-6.

33. Ardashir, J.F.; Sabahi, M.; Hosseini, S.H.; Blaabjerg, F.; Babaei, E.; Gharehpetian, G.B. A Single-Phase Transformerless Inverter with Charge Pump Circuit Concept for Grid-Tied PV Applications. IEEE Trans. Ind. Electron. 2017, 64, 5403-5415. [CrossRef]

34. Zhang, D.; Li, J.; Hui, D. Coordinated control for voltage regulation of distribution network voltage regulation by distributed energy storage systems. Prot. Control Mod. Power Syst. 2018, 3, 3. [CrossRef]

(C) 2019 by the authors. Licensee MDPI, Basel, Switzerland. This article is an open access article distributed under the terms and conditions of the Creative Commons Attribution (CC BY) license (http://creativecommons.org/licenses/by/4.0/). 